\title{
Doxylamine succinate-pyridoxine hydrochloride (Diclegis) for the management of nausea and vomiting in pregnancy: an overview
}

This article was published in the following Dove Press journal:

International Journal of Women's Health

12 April 2014

Number of times this article has been viewed

\section{Nina Nuangchamnong Jennifer Niebyl}

Department of Obstetrics and Gynecology, University of lowa Hospitals and Clinics, lowa, IA, USA
Correspondence: Nina Nuangchamnong Department of Obstetrics and Gynecology, University of lowa Hospitals and Clinics, 200 Hawkins Drive, lowa, IA 52242, USA Email nina-nuangchamnong@uiowa.edu

\begin{abstract}
Nausea and vomiting in pregnancy (NVP) is common and often undertreated, in part due to fears of adverse effects of medications on the fetus during early pregnancy. In April 2013, the US Food and Drug Administration (FDA) approved doxylamine succinate $10 \mathrm{mg}$ and pyridoxine hydrochloride (a vitamin $\mathrm{B}_{6}$ analog) $10 \mathrm{mg}$ as a delayed-release combination pill called Diclegis for the treatment of NVP. Diclegis is currently the only medication that is FDA-approved for the indication of NVP. This review addresses the historical context, safety, efficacy, pharmacology, and practical role of doxylamine and pyridoxine for the management of NVP. The reintroduction of this doxylamine-pyridoxine combination pill into the American market fills a therapeutic gap in the management of NVP left by the removal of the same active drugs marketed over 30 years ago in the form of Bendectin. The substantial amount of safety data accumulated over the years makes it one of the few drugs that qualify for FDA Pregnancy Category A status. In the hierarchical approach to pharmacological treatment of NVP, the combination of doxylamine and pyridoxine should thus be first-tier.
\end{abstract}

Keywords: doxylamine, pyridoxine, vitamin $\mathrm{B}_{6}$, nausea, vomiting, pregnancy

\section{Introduction}

Nausea and vomiting in pregnancy (NVP) is common. A recent estimate of the prevalence of NVP in the US is $70 \% .{ }^{1}$ A recent estimate of the total economic burden in the US in 2012, including drug treatments for mild-to-severe NVP, hospitalizations for hyperemesis gravidarum, time lost from work, and caregiver time, is $\$ 1.7$ billion. ${ }^{2}$ Estimates of prevalence and economic burden due to NVP are similarly high in developing countries. ${ }^{3,4}$

NVP is a spectrum disorder. It is colloquially referred to as "morning sickness", but in one study only $1.8 \%$ of women reported nausea limited to mornings alone, whereas $80 \%$ reported nausea lasting all day. ${ }^{5}$ Only $50 \%$ of women experienced relief by 14 weeks' gestation; $90 \%$ of those affected had relief by 22 weeks' gestation. ${ }^{5}$ In another study, about $25 \%$ of women had nausea alone, and $50 \%$ had both nausea and vomiting. ${ }^{6}$ Although NVP is generally considered part of a healthy pregnancy, the potential negative effect on the pregnant woman's quality of life is significant. ${ }^{7,8}$ Approximately $1 \%$ of pregnant women develop a severe form of NVP called hyperemesis gravidarum with dehydration, weight loss, and ketonuria. Some cases of hyperemesis gravidarum may by avoided by aggressive early treatment of NVP.

The fear of potential teratogenicity necessitates a proven safe pharmacologic intervention for NVP during the vulnerable period of organogenesis. The period from onset to peak severity of NVP (from 8 to 10 weeks' gestation) ${ }^{6}$ overlaps with 
the period of fetal organogenesis (from 4 to 10 weeks' gestation). The etiology of NVP is unknown, but there is a close temporal relationship between peak human chorionic gonadotropin concentrations and peak symptoms of NVP, so human chorionic gonadotropin has been considered a likely candidate for the emetogenic stimulus arising from the placenta. ${ }^{9}$ Interestingly, NVP itself has not been observed to be associated with an increased risk of birth defects. ${ }^{10}$

Many dietary and pharmacologic treatment regimens are available. The American Congress of Obstetricians and Gynecologists has published a stepwise algorithm for pharmacologic treatment of NVP, recommending pyridoxine (vitamin $\mathrm{B}_{6}$ ) and doxylamine as first-line agents when conservative treatment with dietary and lifestyle changes is unsuccessful. ${ }^{9}$ In April 2013, the US Food and Drug Administration (FDA) approved Diclegis ${ }^{\circledR}$ (Duchesnay USA Inc., Rosemont, PA, USA), a combination of delayed-release doxylamine succinate and pyridoxine hydrochloride, for the treatment of NVP. Diclegis is the only antiemetic with FDA Pregnancy Category A status, indicating that adequate and well-controlled studies have failed to demonstrate a risk to the fetus in the first trimester of pregnancy (and there is no evidence of risk in later trimesters). This review addresses the historical context, safety, efficacy, pharmacology, and practical role of doxylamine and pyridoxine for the management of NVP.

\section{History of Bendectin}

Diclegis is a reincarnation of the drug combination previously marketed, and unfairly maligned, in the US under the brand name Bendectin (Merrell Dow Pharmaceuticals, Kansas, MO, USA). Diclegis contains the same active ingredients as Bendectin and has the same indication. Great effort has been put into demonstrating the safety of Diclegis due to previous experience with another drug used for NVP called thalidomide. Thalidomide was never approved or licensed by the FDA for use in the US, but thousands of pregnant women in the US in the 1950s had access to thalidomide through clinical trials and from other countries. The offspring of women who used thalidomide for NVP developed major anomalies, most commonly bilateral limb reductions called phocomelia. Although the application to the FDA for approval of the drug was withdrawn, the teratogenicity of thalidomide had a major influence on the development and use of any medication during early pregnancy thereafter. ${ }^{11}$

Bendectin was FDA-approved in 1956 for treatment of NVP. The original formulation included doxylamine succinate, pyridoxine hydrochloride, and dicyclomine hydrochloride. After studies showing no benefit of dicyclomine, which is an antispasmodic agent, Bendectin was reformulated in 1976 to contain only doxylamine and pyridoxine. Bendectin became a leading treatment for NVP in the US as well as other countries under different trade names. It was known as Debendox in the UK and Australia, and as Lenotan in Germany, Switzerland, and other countries in Europe, South America, and Africa. In the 1970s, a number of lawsuits were filed alleging that Bendectin, like thalidomide, was responsible for congenital defects. Unlike claims against thalidomide, however, the claims against Bendectin were for multiple defects and biologically implausible. One of the cases that received widespread publicity alleged that Bendectin use during pregnancy caused unilateral fetal limb reduction, which is not biologically plausible because limb defects caused by drug exposure would be bilateral. Despite a lack of scientific evidence, the number of lawsuits grew. In 1983, the manufacturer of Bendectin elected to discontinue production of Bendectin, not because Bendectin was hazardous, but because insurance premiums had become untenable. ${ }^{11}$

While Bendectin was available in the US from 1958 to 1983 , it is estimated that $25 \%-30 \%$ of all pregnant women received this medication. The 1980 National Ambulatory Medical Care Survey indicated that Bendectin accounted for $82 \%$ of the antiemetic use for NVP that year. After the discontinuation of Bendectin, hospital admissions for excessive vomiting in pregnancy doubled from 1980 to 1985, the period when Bendectin use declined and ceased in the US. Overall antiemetic use for NVP dropped 90\% during that time, due to the absence of Bendectin and failure of any other antiemetic to fill the void. During that period, birth-defect rates remained constant (Figure 1). ${ }^{12}$

\section{Safety of doxylamine and pyridoxine}

Although Bendectin was withdrawn from the US market due to lawsuits that alleged a teratogenic effect, no other agents given in pregnancy have more conclusive safety data with regard to teratogenicity (Table 1 ). ${ }^{13}$ Since the withdrawal of Bendectin from the American market, the FDA has twice indicated, in 1983 and in 1999, that the medication had not been withdrawn from sales due to lack of safety or effectiveness. Teratologic studies in rabbits and rats, as well as extensive epidemiologic studies, have produced no evidence that exposure to any of the components of Bendectin in the first trimester of pregnancy causes an increase in 


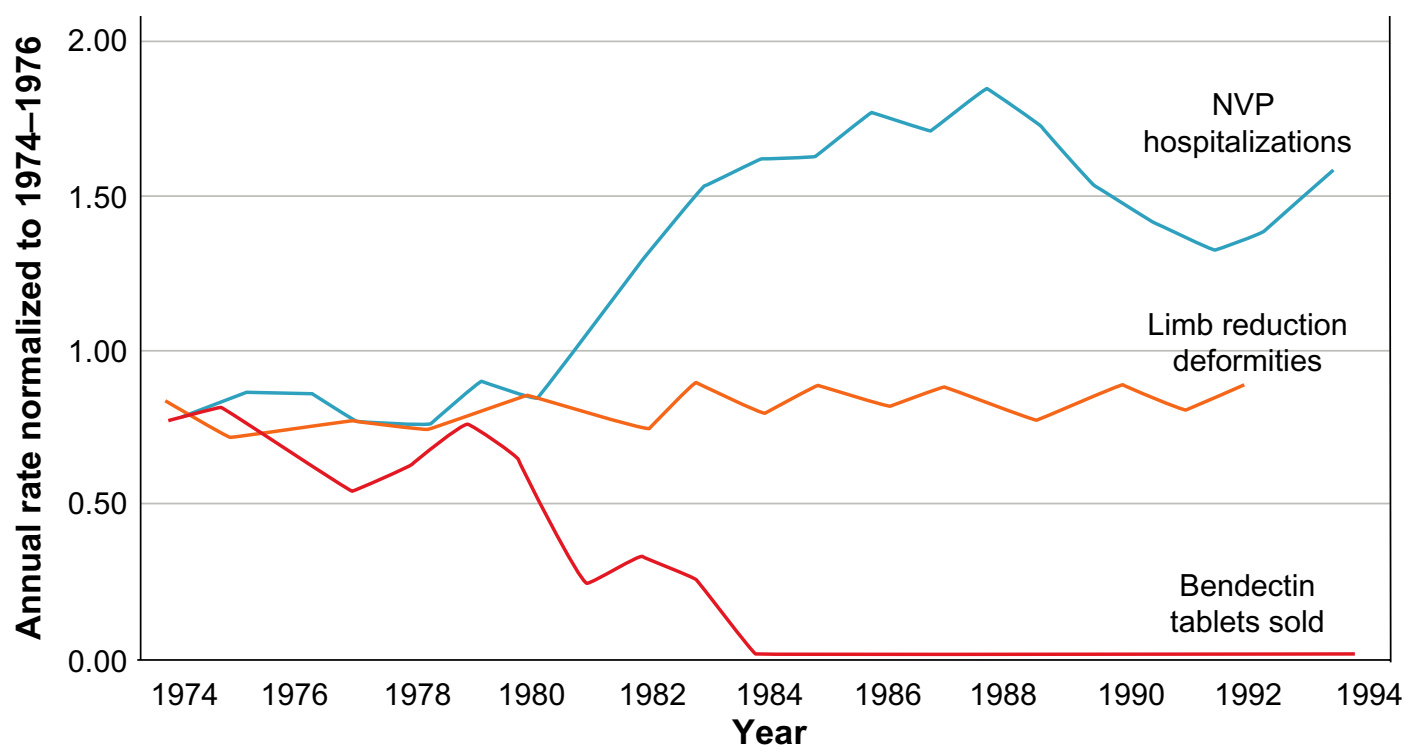

Figure I Public health data related to Bendectin therapy.

Notes: NVP hospitalization data were collected by the National Center for Health Statistics. Birth defect data were collected by the Centers for Disease Control. Bendectin sales data were collected by the Food and Drug Administration. Reproduced with permission from Kutcher JS, Engle A, Firth J, Lamm SH. Bendectin and birth defects. II: Ecological analyses. Birth Defects Res A Clin Mol Teratol. 2003;67(2):88-97. @ 2003 Wiley-Liss, Inc., A Wiley Company. ${ }^{12}$

Abbreviation: NVP, nausea and vomiting in pregnancy.

Table I Summary of selected cited studies

\begin{tabular}{|c|c|c|}
\hline Study & Design & Results \\
\hline \multicolumn{3}{|l|}{ Safety } \\
\hline Einarson et al ${ }^{15}$ & Meta-analysis & $\begin{array}{l}\text { No association between birth defects and first-trimester } \\
\text { Bendectin exposure (OR I.0I [ } 95 \% \mathrm{Cl} 0.66-1.55])\end{array}$ \\
\hline McKeigue et $\mathrm{a}^{16}$ & Meta-analysis & $\begin{array}{l}\text { No association between birth defects and first-trimester } \\
\text { Bendectin exposure (RR } 0.95 \text { [95\% Cl 0.88-1.04]) }\end{array}$ \\
\hline Atanackovic et al ${ }^{19}$ & Prospective cohort & $\begin{array}{l}\text { No increase in incidence of maternal adverse effects or pregnancy } \\
\text { outcome with higher-than-standard doses of Diclectin }\end{array}$ \\
\hline Nulman et $\mathrm{al}^{20}$ & Prospective cohort & $\begin{array}{l}\text { Children of mothers treated with Diclectin for NVP scored } \\
\text { within normal reference ranges for neurodevelopmental outcome }\end{array}$ \\
\hline \multicolumn{3}{|l|}{ Efficacy } \\
\hline Sahakian et $\mathrm{a}^{23}$ & $\begin{array}{l}\text { Randomized, double-blind, } \\
\text { placebo-controlled trial }\end{array}$ & $\begin{array}{l}\text { Vitamin } B_{6} \text { use ( } 25 \mathrm{mg} \text { three times daily) resulted in a larger } \\
\text { improvement in women with severe NVP compared with } \\
\text { placebo based on visual analog scale score (mean } 4.3 \pm 2.1 \\
\text { versus } 1.8 \pm 2.2[P<0.0 \mathrm{I}] \text { ) }\end{array}$ \\
\hline Vutyavanich et $\mathrm{al}^{24}$ & $\begin{array}{l}\text { Randomized, double-blind, } \\
\text { placebo-controlled trial }\end{array}$ & $\begin{array}{l}\text { Pyridoxine use ( } 10 \mathrm{mg} \text { three times daily) resulted in a larger } \\
\text { improvement in symptoms of NVP compared with placebo } \\
\text { based on visual analog scale score (mean } 2.9 \pm 2.2 \text { versus } 2.0 \pm 2.7 \\
{[P<0.0008] \text { ) }}\end{array}$ \\
\hline Koren et $\mathrm{al}^{17}$ & $\begin{array}{l}\text { Randomized, double-blind, } \\
\text { multicenter placebo- } \\
\text { controlled trial }\end{array}$ & $\begin{array}{l}\text { Diclectin use resulted in larger improvement in symptoms of } \\
\text { NVP compared with placebo based on PUQE score }(-4.8 \pm 2.7 \\
\text { versus }-3.9 \pm 2.6[P=0.006]) \text { and quality of life }\end{array}$ \\
\hline Ashkenazi-Hoffnung et $\mathrm{a}^{22}$ & Prospective cohort & $\begin{array}{l}\text { Doxylamine } 25 \mathrm{mg} \text { and pyridoxine } 50 \mathrm{mg} \text { (both used twice } \\
\text { daily) showed similar efficacy compared with metoclopramide } \\
\text { for alleviation of NVP ( } 20 \text { of } 29 \text { [69\%] versus I } 8 \text { of } 25[72 \%] \text { of } \\
\text { women }[P=0.65] \text { ) }\end{array}$ \\
\hline Maltepe et $\mathrm{al}^{28}$ & Randomized controlled trial & $\begin{array}{l}\text { Preemptive Diclectin use resulted in } 2.5 \text {-fold fewer cases of } \\
\text { moderate-severe cases of NVP compared to controls ( } 15.4 \% \\
\text { versus } 39.13 \%[P=0.05]) \text { and more women with resolution of } \\
\text { NVP before delivery }(78.2 \% \text { versus } 50 \%[P<0.002])\end{array}$ \\
\hline
\end{tabular}

Abbreviations: OR, odds ratio; $\mathrm{Cl}$, confidence interval; RR, relative risk; NVP, nausea and vomiting in pregnancy; PUQE, pregnancy-unique quantification of emesis. 
malformations, stillbirths, or growth restriction in exposed fetuses compared to controls. ${ }^{14}$ Many studies have confirmed the fetal safety of this drug combination, including two meta-analyses. The first meta-analysis in 1988 gave an overall summary odds ratio of 1.01 (95\% confidence interval [CI] 0.66-1.55). ${ }^{15}$ The second meta-analysis combined data from all the cohort and case-control studies reported through 1993, and estimated the relative risk of any malformation at birth in association with exposure to Bendectin in the first trimester to be 0.95 (95\% CI 0.88-1.04). ${ }^{16}$ Therefore, those studies as a group showed no difference in the risk of birth defects between those infants whose mothers had taken Bendectin during the first trimester of pregnancy and those infants whose mothers had not. The drug combination of doxylamine and pyridoxine has been studied in a total of over 200,000 pregnant women, which is more than any other drug, for any indication, in pregnancy. ${ }^{17}$

The Canadian generic version of the delayed-release formulation of doxylamine and pyridoxine, Diclectin ${ }^{\circledR}$ (Duchesnay), has remained available as the first-line treatment $^{18}$ for NVP in Canada without any reports of it causing fetal anomalies in continuing reviews. Bendectin, Diclectin, and Diclegis all contain the same active ingredients in the same dosages, but the current Diclectin and Diclegis formulation reflects modern manufacturing technology for a delayed-release tablet. One observational, prospective study of the delayed-release combination of doxylamine and pyridoxine showed that higher-than-standard doses, when calculated per kilogram of body weight, do not affect either the incidence of maternal adverse effects or pregnancy outcome. ${ }^{19}$ One prospective cohort study of motherchild pairs was conducted to determine the effects of NVP and its treatment with Diclectin on child neurodevelopment, and found no adverse effect on children's cognitive abilities upon follow-up at ages 3-7 years. ${ }^{20}$

\section{Efficacy of doxylamine and pyridoxine}

In general, there has been a lack of high-quality evidence to support the effectiveness of any specific intervention in NVP, ${ }^{21}$ but available data support the efficacy of doxylamine and pyridoxine as an antiemetic for mild-to-moderate NVP (Table 1). A randomized controlled trial of the effectiveness of the delayed-release combination of doxylamine succinate $10 \mathrm{mg}$ and pyridoxine hydrochloride $10 \mathrm{mg}$ (Diclectin) for NVP was crucial for its reintroduction by the FDA into practice in the US. The only previous randomized studies conducted on Bendectin about 40 years ago were submitted to the FDA without publication in peer-reviewed literature. In 2010, a randomized, double-blind, multicenter, placebo-controlled trial in the US enrolled 261 patients in the gestational age range of 7-14 weeks. The study used a two-part pregnancyunique quantification of emesis (PUQE) score, which is the only validated scoring system that incorporates both the physical (nausea, vomiting, retching) and quality-of-life aspects of NVP. The PUQE scoring system has been widely used and has been validated for use in both English and Spanish. In this study, Diclectin use resulted in a significantly larger improvement in symptoms of NVP compared with placebo over 15 days based on both the clinical PUQE score (scale $3-15)(-4.8 \pm 2.7$ PUQE score versus $-3.9 \pm 2.6 ; P=0.006)$ and global assessment of well-being (scale $1-10)(2.8 \pm 2.8$ versus $1.8 \pm 2.2 ; P=0.005) .{ }^{17}$ At the end of the 15 -day trial, $48.9 \%$ of the 131 women receiving Diclectin asked to continue compassionate use of their medication, compared with $32.8 \%$ of the 125 placebo-control women $(P=0.009)$. Women on the drug required fewer alternative treatments, and also reported missing less time from work. ${ }^{17} \mathrm{~A}$ smaller prospective cohort study conducted in Israel between 2008 and 2010 followed 163 women who contacted a free call-in center for queries regarding drug use during pregnancy and lactation. They compared a combination of doxylamine and pyridoxine taken from commercially available over-the-counter preparations in Israel (pyridoxine $50 \mathrm{mg}$ and doxylamine succinate $25 \mathrm{mg}$ ) with metoclopramide. They found no difference in reported efficacy $(69 \%$ versus $72 \%, P=0.65) .{ }^{22}$

Two controlled trials have shown efficacy of vitamin $B_{6}$ (pyridoxine) alone for NVP. The first study was a randomized, double-blind, placebo-controlled trial in the US. Fifty-nine patients with NVP were randomized to either vitamin $B_{6}$ or placebo at a dose of $25 \mathrm{mg}$ three times a day for 3 days. Half of the patients stopped vomiting, and most patients with severe nausea reported diminution to mild or moderate nausea by the visual analog scale. ${ }^{23}$ This trial was repeated a few years later in Thailand with a larger sample size. The investigators randomized 342 women to take vitamin $\mathrm{B}_{6}$ $10 \mathrm{mg}$ three times a day or placebo for 5 days. They showed a significant decrease in nausea by the visual analog scale. ${ }^{24}$ Despite demonstrated efficacy, the mechanism for how pyridoxine works as an antiemetic in NVP is unknown. Interestingly, a prospective study of 180 women found no difference between serum indicators of vitamin $\mathrm{B}_{6}$ status and the incidence or degree of morning sickness. ${ }^{25}$ Two other studies have found that women who were taking a multivitamin at the time of conception were less likely to need medical attention for vomiting. ${ }^{26,27}$ Although the etiology of 
NVP has not been linked to deficiency of a specific vitamin, the American Congress of Obstetricians and Gynecologists recommends that women with a history of NVP or hyperemesis gravidarum in a prior pregnancy be advised to take a multivitamin at the time of the next conception. ${ }^{9}$ A recent randomized control trial studied women who had experienced severe NVP and/or hyperemesis gravidarum in a prior pregnancy. One group preemptively started Diclectin with a positive pregnancy test, and the control group started Diclectin only with the first symptoms of NVP. There were 2.5-fold fewer cases of moderate-severe cases of NVP in the preemptive group than in the control group (15.4\% versus $39.13 \%, P=0.05) .^{28}$

\section{Pharmacology of Diclegis}

The two active ingredients, doxylamine and pyridoxine, are unrelated, but appear to have a synergistic effect in the alleviation of NVP. Doxylamine is an antihistamine that blocks $\mathrm{H}_{1}$ receptors. In general, antihistamines directly inhibit the action of histamine at the $\mathrm{H}_{1}$ receptor and indirectly affect the vestibular system, decreasing stimulation of the vomiting center. Muscarinic receptor inhibition may also play a role in antihistamine antiemetic activity. ${ }^{29}$ Pyridoxine (vitamin $\mathrm{B}_{6}$ ) is a water-soluble vitamin that is an essential coenzyme for the metabolism of amino acids, lipids, and carbohydrates. How pyridoxine exerts antiemetic effects is unclear.

The recommended starting dose for Diclegis is two tablets taken at bedtime, when NVP tends to be minimal. Both doxylamine and pyridoxine are conveniently delayed for release in the morning, the most common time for NVP. If symptoms are not adequately controlled, the dose can be increased by adding one tablet in the morning. If symptoms are still not adequately controlled, another tablet can be added in the afternoon to a maximum recommended dose of four tablets daily. Due to the delayed-release preparation, the tablets should not be crushed, chewed, or split. Although the maximum recommended dose is four tablets per day, current common practice with Diclectin in Canada allows for adjustment for severity of symptoms and/or maternal body mass index. One study showed that if the patient has a higher body mass index, she may take up to eight to 12 tablets a day without increasing maternal adverse effects, fetal risks, degree of tiredness, or birth defects. ${ }^{19}$

Dosing of the delayed-release combination of doxylamine and pyridoxine (Diclectin or Diclegis) is timed so that onset of action is most likely to occur in the early morning, when NVP symptoms are commonly at their peak. The half-life of doxylamine in the delayed-release tablet is 11.7 hours, and the half-life of pyridoxal $5^{\prime}$-phosphate (an active metabolite of pyridoxine) is 56 hours. ${ }^{30}$ However, there is some variability in its onset and duration of action among women. It is estimated that the oral bioavailability of pyridoxine is $100 \%$, so interindividual differences in metabolism, rather than bioavailability, are thought to account for variation in therapeutic response. ${ }^{31}$ Both doxylamine and pyridoxine are hepatically cleared. A recent study compared the pharmacokinetics of doxylamine and pyridoxine in nonpregnant women of reproductive age and women in their first trimester of pregnancy with a diagnosis of NVP. There were no statistically significant differences in apparent clearance rates for doxylamine or pyridoxine in pregnant and nonpregnant women. ${ }^{30}$

\section{Adverse effects and warnings}

Reported adverse effects of doxylamine and pyridoxine delayed-release tablets include somnolence, headache, dizziness, dry mouth, and hypersensitivity. According to the package insert, doxylamine and pyridoxine delayedrelease tablets are contraindicated in women with known hypersensitivity to doxylamine, other ethanolaminederivative antihistamines, or pyridoxine. It is also contraindicated in combination with monoamine oxidase inhibitors, which intensify and prolong the adverse central nervous system effects. Monoamine oxidase inhibitors may also prolong and intensify the anticholinergic (drying effects) of such antihistamines as doxylamine. This medication may cause somnolence due to the anticholinergic properties of doxylamine. Use of this medication is not recommended if a woman is concurrently using central nervous system depressants, such as alcohol or sedating medications, including other antihistamines (that may be in cough and cold medications), opiates, or sleep aids. This medication has anticholinergic properties, and should be used with caution in women who have 1) asthma, 2) increased intraocular pressure, 3) narrowangle glaucoma, 4) stenosing peptic ulcer, 5) pyloroduodenal obstruction, or 6) bladder-neck obstruction.

\section{Comparison to other antiemetics}

The patient's perception of the severity of her symptoms plays a critical role in whether, when, and how to treat NVP. The individual components doxylamine and pyridoxine are readily available over the counter in the US, and had been used "off-label" for the treatment of NVP long before the introduction of Diclegis. Currently, the generic forms of pyridoxine and doxylamine cost much less than the brand name Diclegis (Table 2). Potential disadvantages of using generic, 
Table 2 Costs of antiemetics

\begin{tabular}{|c|c|c|}
\hline Drug name & Formulations & $\begin{array}{l}\text { Cost (30 tablets), } \\
\text { US\$ }\end{array}$ \\
\hline $\begin{array}{l}\text { Vitamin } \mathrm{B}_{6} \\
\text { (pyridoxine } \\
\text { hydrochloride) }\end{array}$ & $\begin{array}{l}\text { Oral tablet: } 25 \text { mg, } \\
50 \mathrm{mg}, 100 \mathrm{mg}, 200 \mathrm{mg} \text {, } \\
250 \mathrm{mg}, 500 \mathrm{mg} \\
\text { Oral tablet, extended } \\
\text { release: } 200 \mathrm{mg}\end{array}$ & $\$ 0.73$ \\
\hline $\begin{array}{l}\text { Doxylamine succinate } \\
\left(\text { Unisom SleepTabs }{ }^{\circledR}\right)\end{array}$ & Oral tablet: 25 mg & $\$ 4.48$ \\
\hline $\begin{array}{l}\text { Metoclopramide } \\
\left(\operatorname{Reglan}^{\circledR}\right)\end{array}$ & Oral tablet: $10 \mathrm{mg}$ & $\$ 5.00$ \\
\hline $\begin{array}{l}\text { Promethazine } \\
\left(\text { Phenergan }^{\circledR}\right)\end{array}$ & Oral tablet: 25 mg & $\$ 15.00$ \\
\hline $\begin{array}{l}\text { Ondansetron } \\
\left(\text { Zofran }^{\circledR}\right)\end{array}$ & Oral tablet: $4 \mathrm{mg}$ & $\$ 60.00$ \\
\hline $\begin{array}{l}\text { Extended-release } \\
\text { vitamin } B_{6} \text { and } \\
\left.\text { doxylamine (Diclegis }{ }^{\circledR}\right)\end{array}$ & $\begin{array}{l}\text { Oral tablet: } \\
10 \mathrm{mg} / 10 \mathrm{mg}\end{array}$ & $\begin{array}{l}\$ 160.00 \text { (covered } \\
\text { by Medicaid) }\end{array}$ \\
\hline
\end{tabular}

Notes: Reglan ${ }^{\circledast}$ (Ani Pharmaceuticals, Baudette, MN, USA); Phenergan ${ }^{\circledast}$ (Baxter Healthcare Corp., Deerfield, IL, USA); Zofran ${ }^{\circledR}$ (GlaxoSmithKline Pharmaceuticals, Philadelphia, PA, USA).

over-the-counter preparations include the inconvenience of 1) splitting generic tablets into smaller doses, 2) needing multiple tablets, 3) identifying the correct over-the-counter drug to use, and 4) lack of delayed-release effects. For example, Unisom ${ }^{\circledR}$ (Chattem, Inc., Chattanooga, TN, USA) has four sleep-aid medications with similar names (SleepTabs ${ }^{\circledR}$, SleepGels $^{\circledR}$, SleepMelts ${ }^{\mathrm{TM}}$, and PM Pain SleepCaps $\left.{ }^{\mathrm{TM}}\right)$. Only SleepTabs are comprised of doxylamine; the other three have diphenhydramine hydrochloride as the active ingredient. In the US, Diclegis is fully covered by Medicaid insurance due to its FDA Pregnancy Category A status.

If pyridoxine and doxylamine are insufficient to treat a patient's symptoms, then stepwise escalation of pharmacologic therapies is recommended, assuming that other causes of nausea and vomiting have been excluded. For hyperemesis gravidarum or dehydration, intravenous fluid replacement with thiamine is necessary, along with other antiemetics (Figure 2).

\section{Antihistamines}

Other antihistamines, such as diphenhydramine, dimenhydrinate, meclizine, or hydroxyzine, can be substituted for doxylamine if treatment with pyridoxine and doxylamine is inadequate to control symptoms. Substitution of doxylamine, rather than addition to, is preferred to minimize somnolence. None of these agents have been shown to be teratogenic. ${ }^{32}$

\section{Phenothiazines}

Promethazine or prochlorperazine is often prescribed if antihistamines fail. Studies show that promethazine is as effective as metoclopramide ${ }^{33}$ and ondansetron ${ }^{34}$ in the treatment of hyperemesis gravidarum, but is generally more sedating than the other two medications, and thus may be less desirable. Multiple observational studies of patients exposed to various phenothiazines have failed to demonstrate an increased risk for major malformations ${ }^{35}$ Promethazine has a "black-box warning" for severe tissue injuries with intravenous or subcutaneous administration. Oral, rectal, or intramuscular administration of promethazine is thus preferred.

\section{Dopamine antagonists}

Metoclopramide is also often prescribed if antihistamines fail. Metoclopramide is a prokinetic agent that has long been used in Europe and Israel for NVP. One randomized controlled trial comparing metoclopramide and promethazine for the treatment of hyperemesis gravidarum showed no difference in efficacy, but metoclopramide was less sedating. ${ }^{33}$ There have been no safety concerns specific to pregnancy. ${ }^{32}$ The largest study to date was published in 2013, with 28,486 first-trimester exposures and no increased risk of major congenital malformations. ${ }^{36}$ Metoclopramide has been associated in rare cases with tardive dyskinesia, and it has a black-box warning for this reason. The risk of development of this maternal complication increases with duration of treatment and total cumulative dose, so its use should not extend beyond 12 weeks.

\section{5-hydroxytryptamine 3-receptor antagonists}

Ondansetron is FDA-approved for use in treating chemotherapy-induced and postoperative nausea and vomiting, but there is increasing information about its use in pregnancy. One randomized trial comparing ondansetron and promethazine in pregnancy showed similar efficacy between the two, but ondansetron was less sedating. ${ }^{34}$ In 2011, data from the National Birth Defects Prevention Study (a multisite, population-based, case-control study in the US) suggested an increased risk for cleft palate (adjusted odds ratio $2.37,95 \%$ CI 1.18-4.76) among women treated with ondansetron for NVP in the first trimester. ${ }^{10}$ The largest study to date, published in February 2013, utilized data from Danish pregnancy, birth, and prescription registries. There were 1,233 first-trimester exposures between 2004 and 2011, and there was no increased risk of major congenital malformations in offspring of exposed compared to unexposed women $(2.9 \%$ versus $2.9 \%$, prevalence odds ratio $1.12,95 \%$ CI $0.69-1.82) .{ }^{37}$ However, another group of investigators presented data in August 2013 based on the same Danish 


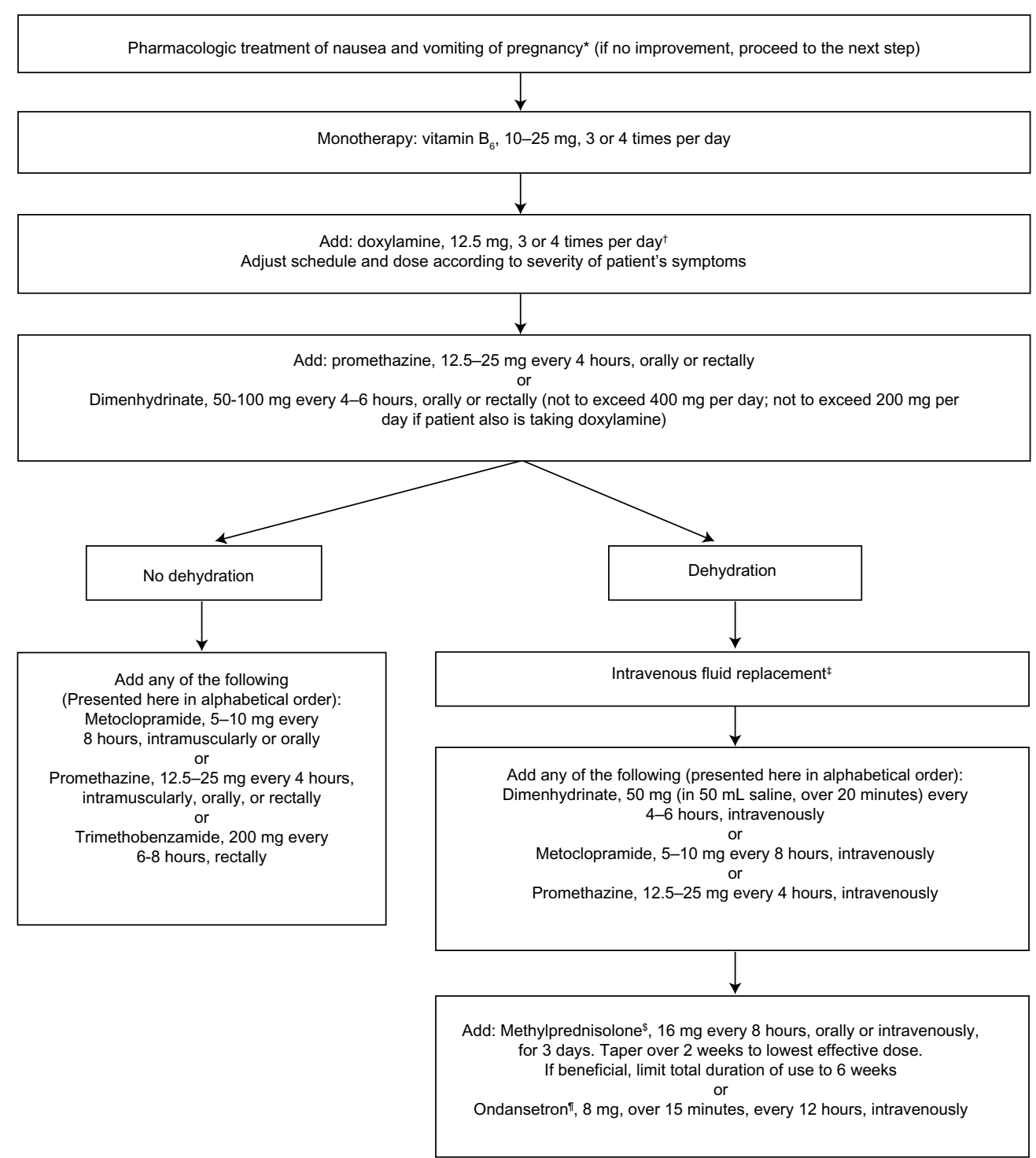

Figure 2 ACOG (American Congress of Obstetricians and Gynecologists) algorithm for pharmacologic treatment of NVP (Nausea and vomiting in pregnancy). Notes: *This algorithm assumes other causes of nausea and vomiting have been ruled out. At any step, consider parenteral nutrition if dehydration or persistent weight loss is noted. Alternative therapies may be added at any time during the sequence depending on patient acceptance and clinician familiarity; consider P6 acupressure with wrist bands or acustimulation or ginger capsules, $250 \mathrm{mg} 4$ times daily; tin the United States, doxylamine is available as the active ingredient in some over-the-counter sleep aids; one half of a scored $25 \mathrm{mg}$ tablet can be used to provide a $12.5 \mathrm{mg}$ dose of doxylamine; 2-3 days (followed by intravenous multivitamins), is recommended for every woman who requires intravenous hydration and has vomited for more than 3 weeks; ${ }^{\$}$ corticosteroids appear to increase risk for oral clefts in the first 10 weeks of gestation; "safety, particularly in the first trimester of pregnancy, not yet determined; less effect on nausea.

registries, but with 1,248 women who filled a prescription for ondansetron during the first trimester between 1997 and 2010. Their data indicate a mildly increased risk for congenital malformations $(3.5 \%$ and $4.7 \%$, adjusted odds ratio 1.3 ), mostly due to a twofold increase in congenital heart defects associated with ondansetron use during the first trimester of pregnancy. ${ }^{38,39}$

\section{Glucocorticoids}

Methylprednisolone is an option in refractory cases or hyperemesis gravidarum after 10 weeks' gestation. A meta-analysis of four studies showed a small increase in risk of cleft lip if used before 10 weeks' gestation, and higher doses were associated with greater risks. ${ }^{40}$ To limit serious maternal side effects, therapy should be limited to 6 weeks.

\section{Alternative therapies}

Alternative therapies may be added at any time during the management of NVP, depending on patient acceptance and clinician familiarity. As an alternative therapy, ginger shows the strongest data. Several controlled trials have compared ginger with placebo, and found a statistically significant 
decrease in NVP in women who took ginger. ${ }^{29,41}$ Two other studies compared ginger with pyridoxine, and found both interventions to be equivalent in the treatment of NVP. ${ }^{29,31}$

\section{Conclusion}

The reintroduction of doxylamine and pyridoxine as a delayed-release combination pill with US FDA Category A status emphasizes its favorable safety profile and bolsters the recommendation that it be used as first-line treatment in the pharmacologic management of NVP. Given the history of thalidomide and Bendectin, it is important to address concerns and alleviate fears about the safety of medications taken in early pregnancy so that quality of life may not be unnecessarily compromised. Doxylamine and pyridoxine have become the most studied drugs for NVP, and their use may alleviate many women's symptoms without the need for escalation to other medications that, while also effective, do not have as robust a safety profile.

\section{Disclosure}

Dr Niebyl has received honoraria for lecturing from Medavera, MedEdNow, and Science First, all medical education companies who have received educational grants from Duchesnay, maker of Diclegis. The authors report no other conflicts of interest in this work.

\section{References}

1. Einarson TR, Piwko C, Koren G. Prevalence of nausea and vomiting of pregnancy in the USA: a meta analysis. J Popul Ther Clin Pharmacol. 2013;20(2):e163-e170.

2. Piwko C, Koren G, Babashov V, Vicente C, Einarson TR. Economic burden of nausea and vomiting of pregnancy in the USA. J Popul Ther Clin Pharmacol. 2013;20(2):e149-e160.

3. Agampodi S, Agampodi T, Wickramasinghe N, et al. Productivity cost due to maternal ill health in Sri Lanka. PLoS One. 2012;7(8):e42333.

4. Agampodi SB, Wickramasinghe ND, Horton J, Agampodi TC. Minor ailments in pregnancy are not a minor concern for pregnant women: a morbidity assessment survey in rural Sri Lanka. PLoS One. 2013;8(5):e64214.

5. Lacroix R, Eason E, Melzack R. Nausea and vomiting during pregnancy: a prospective study of its frequency, intensity, and patterns of change. Am J Obstet Gynecol. 2000;182(4):931-937.

6. Gadsby R, Barnie-Adshead AM, Jagger C. A prospective study of nausea and vomiting during pregnancy. Br J Gen Pract. 1993;43(371): 245-248.

7. Wood H, McKellar LV, Lightbody M. Nausea and vomiting in pregnancy: blooming or bloomin' awful? A review of the literature. Women Birth. 2013;26(2):100-104.

8. McCarthy FP, Khashan AS, North RA, et al. A prospective cohort study investigating associations between hyperemesis gravidarum and cognitive, behavioural and emotional well-being in pregnancy. PLoS One. 2011;6(11):e27678.

9. American College of Obstetrics and Gynecology. ACOG (American College of Obstetrics and Gynecology) Practice Bulletin: nausea and vomiting of pregnancy. Obstet Gynecol. 2004;103(4):803-814.
10. Anderka M, Mitchell AA, Louik C, Werler MM, Hernández-Diaz S, Rasmussen SA. Medications used to treat nausea and vomiting of pregnancy and the risk of selected birth defects. Birth Defects Res A Clin Mol Teratol. 2012;94(1):22-30.

11. Hale RW, Niebyl J. Bendectin: how a safe and effective drug was removed from the market by our legal system. ACOG Clin Rev. 2012; 17(5):25-27.

12. Kutcher JS, Engle A, Firth J, Lamm SH. Bendectin and birth defects. II: Ecological analyses. Birth Defects Res A Clin Mol Teratol. 2003;67(2): 88-97.

13. Brent RL. Bendectin: review of the medical literature of a comprehensively studied human nonteratogen and the most prevalent tortogen-litigen. Reprod Toxicol. 1995;9(4):337-349.

14. Holmes LB. Teratogen update: bendectin. Teratology. 1983;27(2): 277-281.

15. Einarson TR, Leeder JS, Koren G. A method for meta-analysis of epidemiological studies. Drug Intell Clin Pharm. 1988;22(10): 813-824.

16. McKeigue PM, Lamm SH, Linn S, Kutcher JS. Bendectin and birth defects: I. A meta-analysis of the epidemiologic studies. Teratology. 1994;50(1):27-37.

17. Koren G, Clark S, Hankins GD, et al. Effectiveness of delayed-release doxylamine and pyridoxine for nausea and vomiting of pregnancy: a randomized placebo controlled trial. Am JObstet Gynecol. 2010;203(6): 571. e1-e7.

18. Arsenault MY, Lane CA, MacKinnon CJ, et al. The management of nausea and vomiting of pregnancy. J Obstet Gynaecol Can. 2002;24(10):817-831; quiz 832-813.

19. Atanackovic G, Navioz Y, Moretti ME, Koren G. The safety of higher than standard dose of doxylamine-pyridoxine (Diclectin) for nausea and vomiting of pregnancy. J Clin Pharmacol. 2001;41(8): $842-845$.

20. Nulman I, Rovet J, Barrera M, Knittel-Keren D, Feldman BM, Koren G. Long-term neurodevelopment of children exposed to maternal nausea and vomiting of pregnancy and diclectin. J Pediatr. 2009;155(1):45-50, 50. e1-e2.

21. Matthews A, Dowswell T, Haas DM, Doyle M, O'Mathuna DP. Interventions for nausea and vomiting in early pregnancy. Cochrane Database Syst Reviews. 2010;(9):CD007575.

22. Ashkenazi-Hoffnung L, Merlob P, Stahl B, Klinger G. Evaluation of the efficacy and safety of bi-daily combination therapy with pyridoxine and doxylamine for nausea and vomiting of pregnancy. Isr Med Assoc J. 2013;15(1):23-26.

23. Sahakian V, Rouse D, Sipes S, Rose N, Niebyl J. Vitamin B6 is effective therapy for nausea and vomiting of pregnancy: a randomized, double-blind placebo-controlled study. Obstet Gynecol. 1991; 78(1):33-36.

24. Vutyavanich T, Wongtra-Ngan S, Ruangsri R. Pyridoxine for nausea and vomiting of pregnancy: a randomized, double-blind, placebo-controlled trial. Am J Obstet Gynecol. 1995;173(3 Pt 1):881-884.

25. Schuster K, Bailey LB, Dimperio D, Mahan CS. Morning sickness and vitamin B6 status of pregnant women. Hum Nutr Clin Nutr. 1985;39(1): 75-79.

26. Czeizel AE, Dudas I, Fritz G, Técsöi A, Hanck A, Kunovits G. The effect of periconceptional multivitamin-mineral supplementation on vertigo, nausea and vomiting in the first trimester of pregnancy. Arch Gynecol Obstet. 1992;251(4):181-185.

27. Emelianova S, Mazzotta P, Einarson A, Koren G. Prevalence and severity of nausea and vomiting of pregnancy and effect of vitamin supplementation. Clin Invest Med. 1999;22(3):106-110.

28. Maltepe C, Koren G. Preemptive treatment of nausea and vomiting of pregnancy: results of a randomized controlled trial. Obstet Gynecol Int. 2013;2013:809787.

29. Badell ML, Ramin SM, Smith JA. Treatment options for nausea and vomiting during pregnancy. Pharmacotherapy. 2006;26(9): $1273-1287$ 
30. Matok I, Clark S, Caritis S, et al. Comparing the pharmacokinetics of doxylamine/pyridoxine delayed-release combination in nonpregnant women of reproductive age and women in the first trimester of pregnancy. J Clin Pharmacol. 2013;53(3):334-338.

31. Gill SK, Garcia-Bournissen F, Koren G. Systemic bioavailability and pharmacokinetics of the doxylamine-pyridoxine delayed-release combination (Diclectin). Ther Drug Monit. 2011;33(1):115-119.

32. Niebyl JR. Clinical practice. Nausea and vomiting in pregnancy. $N E n g l$ J Med. 2010;363(16):1544-1550.

33. Tan PC, Khine PP, Vallikkannu N, Omar SZ. Promethazine compared with metoclopramide for hyperemesis gravidarum: a randomized controlled trial. Obstet Gynecol. 2010;115(5):975-981.

34. Sullivan CA, Johnson CA, Roach H, Martin RW, Stewart DK, Morrison JC. A pilot study of intravenous ondansetron for hyperemesis gravidarum. Am J Obstet Gynecol. 1996;174(5):1565-1568.

35. Mazzotta P, Magee LA. A risk-benefit assessment of pharmacological and nonpharmacological treatments for nausea and vomiting of pregnancy. Drugs. 2000;59(4):781-800
36. Pasternak B, Svanström H, Mølgaard-Nielsen D, Melbye M, Hviid A Metoclopramide in pregnancy and risk of major congenital malformations and fetal death. JAMA. 2013;310(15):1601-1611.

37. Pasternak B, Svanstrom H, Hviid A. Ondansetron in pregnancy and risk of adverse fetal outcomes. $N$ Engl J Med. 2013;368(9):814-823.

38. Andersen JT, Jimenez-Solem E, Andersen NL, Poulsen HE. Ondansetron use in early pregnancy and the risk of congenital malformations - a register based nationwide cohort study. Poster presented at: 29th International Conference on Pharmacoepidemiology and Therapeutic Risk Management; August 25-28, 2013; Montreal, Canada.

39. Koren G. Ondansetron: new and troubling data. Ob Gyn News. Epub October 25, 2013.

40. Park-Wyllie L, Mazzotta P, Pastuszak A, et al. Birth defects after maternal exposure to corticosteroids: prospective cohort study and metaanalysis of epidemiological studies. Teratology. 2000;62(6):385-392.

41. Niebyl JR, Goodwin TM. Overview of nausea and vomiting of pregnancy with an emphasis on vitamins and ginger. Am J Obstet Gynecol. 2002;186(5 Suppl Understanding):S253-S255.
International Journal of Women's Health

\section{Publish your work in this journal}

The International Journal of Women's Health is an international, peerreviewed open-access journal publishing original research, reports, editorials, reviews and commentaries on all aspects of women's healthcare including gynecology, obstetrics, and breast cancer. The manuscript management system is completely online and includes

\section{Dovepress}

a very quick and fair peer-review system, which is all easy to use. Visit http://www.dovepress.com/testimonials.php to read real quotes from published authors.

\footnotetext{
Submit your manuscript here: http://www.dovepress.com/international-journal-of-womens-health-journal
} 